\title{
O JOGO NA EDUCAÇÃO MATEMÁTICA: DESENVOLVIMENTO DE UM RPG PARA TRABALHAR O CONCEITO DE MOEDA NO ENSINO FUNDAMENTAL
}

\author{
H. ROSETTI JR ${ }^{1}$, G. P. AMARAL ${ }^{2}$, J. SCHIMIGUEL ${ }^{3}$, C. A. MARTINS ${ }^{3 *}$ e C. F. ARAÚJO JR ${ }^{3}$ \\ ${ }^{1}$ Instituto Federal do Espírito Santo-ES \\ ${ }^{2}$ Escola lolanda Silva-ES \\ ${ }^{3}$ UNICSUL-SP \\ ead.adriano@gmail.com*
}

Artigo submetido em outubro/2015 e aceito em dezembro/2015

DOI: $10.15628 /$ holos.2015.3607

\section{RESUMO}

O JOGO NA EDUCAÇÃO MATEMÁTICA. As aulas de matemática podem reunir importantes discussões a respeito de finanças, das operações monetárias e dos significados em torno da moeda/dinheiro. O presente trabalho tem por objetivo investigar e refletir sobre a questão do dinheiro e do estudo da moeda, em aulas de matemática, no contexto da sala de aula. Além disso, iremos demonstrar um jogo desenvolvido, construído na plataforma RPG Maker VX, que teve o objetivo de promover a investigação e o debate entre professor e aluno em sala de aula. Como resultados preliminares, identificamos que os alunos manifestaram interesse e sensibilidade a respeito do tema moeda/dinheiro, visto que o trato com a moeda/dinheiro se faz presente no dia a dia dos alunos.

PALAVRAS-CHAVE: Jogo, RPG, Educação, Matemática, Conceito de moeda.

\section{THE GAME IN MATHEMATICS EDUCATION: DEVELOPMENT OF A RPG TO WORK CURRENCY CONCEPT IN BASIC EDUCATION}

\begin{abstract}
THE GAME IN MATHEMATICS EDUCATION. The math classes can gather important discussions of finance, monetary operations and meanings around the currency / money. This study aims to investigate and reflect on the question of money and study of money in math classes in the context of the classroom. Also, we will demonstrate a full-fledged game, built in RPG Maker VX platform,
\end{abstract}

which aimed to promote research and discussion between teacher and student in the classroom. As preliminary results, we found that students expressed interest and sensitivity on the subject currency / money, since the deal with the currency / money is present in the daily lives of students. 


\section{INTRODUÇÃO}

Com a globalização, as fronteiras econômicas, financeiras e culturais tornaram-se menores. Percebe-se, mais claramente, o aumento da diferença entre os segmentos sociais depois das intensificações e o desenvolvimento dos meios de comunicação e das novas tecnologias. Ocorre, também, a ampliação das lacunas entre as classes sociais, que são potencializadas pelo sistema de mercado, ao criar sonhos e modelos de consumo.

No momento atual, o assunto educação matemática financeira se faz indispensável, visto o posicionamento das mídias em relação ao consumo. Esse assunto é explorado de maneira a atender os interesses dominantes, tanto pelas mídias televisivas quanto impressas.

Assim, os jovens, inexperientes e sem uma oportunidade para discutir as relações financeiras, assim como as questões sociais, culturais e políticas, apresentam-se influenciados pelas ideias predominantes, em que as relações de mundo são apresentadas de maneira excessivas e descontroladas. Sem planejamento teórico e prático, o trabalho, o lucro e o acúmulo de riqueza se tornam armadilhas para os sujeitos analfabetos matematicamente. Entendemos como analfabeto matemático o sujeito que não consegue utilizar a matemática como ferramenta para entender o mundo à sua volta e, de certa maneira, cria uma relação de dependência com o outro. Nesse cenário, em constante transformação, as escolas, muitas vezes, se posicionam de maneira omissa, deixando de intervir nesse processo de alfabetização matemática. Outras vezes, a escola propicia o debate a respeito dessa alfabetização, tecendo críticas aos modelos econômicos, políticos e sociais predominantes na atualidade. Em outros momentos, a escola reproduz os mecanismos já existentes, que preparam sujeitos matematicamente analfabetos, os chamados analfabetos funcionais. Esses analfabetos funcionais são determinantes para a manutenção dos modelos globalizados, em que o ensino se dá por meio da reprodução do conhecimento, sem uma visão crítica.

O presente artigo, elaborado por alunos do curso de graduação em ciência da computação, teve a assessoria de uma equipe de professores de matemática da educação básica, propondo uma discussão acerca da Educação Matemática Financeira, tendo em vista a formação de cidadãos críticos no ensino fundamental, trazendo a construção do conceito de moeda e seus elementos para a sala de aula.

Com o desenvolvimento tecnológico e a facilidade de acesso à informação, percebe-se a necessidade de mudança do currículo, que, muitas vezes, perpetua o modelo de educação bancária e, em particular, distancia a matemática do cotidiano das demandas da comunidade. E "[...] a experiência revela que com este mesmo sistema só se formam indivíduos medíocres, porque não há estímulo para a criação." (FREIRE, 2003, p. 38). Segundo o referido autor, esse modelo educacional trata os sujeitos como depósito de conhecimento.

Há pouca abordagem por parte de autores de livros didáticos e professores acerca do dinheiro e suas operações quantitativas no cotidiano das atividades escolares, com prejuízo para a formação dos alunos. Esse artigo propõe a utilização da Educação Matemática Financeira, por meio do conceito de moeda como elemento investigativo para uma educação matemática crítica, social e histórica. 


\section{MOEDA E SALA DE AULA}

O assunto "moeda", muitas vezes, não é tratado nas escolas e, quando ocorre, é feito de forma superficial ao trabalhar matemática financeira com porcentagem e exercícios mecânicos de compra e venda. Com isso, a escola não trata, de maneira relevante, a construção do conceito de moeda, visto que uma de suas finalidades "[...] é a educação para a cidadania, e esta educação deve possibilitar aos alunos a compreensão de diversos elementos, dentre eles, os que permitem fazer cálculos para analisar as situações econômicas com as quais convivem em seu dia-a-dia [...]" (BASTOS, 2007, p. 18).

Em Pedagogia do oprimido, Paulo Freire diz que existem dois tipos de educação: a domesticadora e a libertadora. A educação domesticadora consiste em transmitir uma consciência bancária de educação, em que se impõe o saber ao educando. A educação libertadora desenvolve, no aluno, o compromisso consigo mesmo e com o social. O aluno "cria" sua autonomia intelectual, que é reconhecida quando o sujeito é capaz de escolher livremente os meios e os objetivos para o crescimento intelectual e as formas de inserção no mundo, tornando-se sujeito social, isto é, aquele que é tolerante, cooperativo, solidário, humilde, respeitador e justo.

Nos tempos atuais, a instituição pública que mais mantém as características para se formar um sujeito com autonomia intelectual é a escola, a qual deve desenvolver valores universais como a ética, a solidariedade e a justiça.

O papel fundamental da educação no desenvolvimento das pessoas e das sociedades amplia-se ainda mais no atual contexto social e aponta para a necessidade de se construir uma escola voltada para a formação de cidadão por meio da práxis. Neste sentido, os parâmetros curriculares nacionais propõem que "[...] a formação geral, em oposição à formação específica; o desenvolvimento de capacidade de pesquisar, buscar informações, analisá-las e selecioná-las; a capacidade de aprender, criar, formar, ao invés do simples exercício de memorização [...]" (BRASIL, 1999, p. 16)

Os professores de matemática são incumbidos não só da responsabilidade de ensinar os conceitos matemáticos do saber fazer, mas também de trabalhar a reflexão crítica.

Nesse sentido, a educação passa a ser ferramenta fundamental para as transformações sociais e culturais. Podemos perceber essas transformações no Brasil no ano de 2013, mais precisamente no mês de junho, em que o povo brasileiro questiona o alto custo de vida e "luta" pelos seus direitos.

Segundo Skovsmose (2001), a educação matemática é tratada de forma tradicional, o que desenvolve o racionalismo e o objetivismo, os quais se contrapõem ao desenvolvimento político. Devido a esta perspectiva, Skovsmose propõe a interação entre educação matemática e a educação crítica e apresenta uma nova perspectiva, a educação matemática crítica. Para que esse diálogo ocorra, Skovsmose (2001) utiliza a educação matemática como suporte para a democracia, em que as salas de aula de matemática devem pautar-se por parâmetros democráticos. Ole Skovsmose (2010) apresenta duas estratégias "razoáveis" para a prática da Educação Crítica, são elas: tematização e a organização em projetos.

A tematização, segundo o autor, é tratada por meio da cooperação entre os professores que desconstroem o currículo fragmentado. Por outro lado, a estratégia de organização-em- 
projeto dar-se-á por meio da interação entre as disciplinas com o foco na problematização e no trabalho em grupo.

Assim, este artigo propõe do ponto de vista metodológico, uma abordagem investigativa das situações ocorridas em sala na aplicação da atividade para uma Educação Matemática Financeira como estratégia para desenvolver a interação em Educação Matemática e a Matemática Crítica, tendo em vista a aproximação entre a matemática científica e a matemática do cotidiano e a relevância social para os alunos, ao tomar decisões sobre as questões financeiras, desenvolvendo sujeitos conscientes de seu papel como cidadão. Isso promove uma interação direta entre professor e aluno e os resultados foram analisados pelo pesquisador e demonstrados neste artigo.

Promover cidadania é fazer com que o aluno entenda as possibilidades para o trato do dinheiro, tornando-o um sujeito preparado para a vida social, ao decidir sobre a situação financeira atual ou futura. Deste modo, a Educação Matemática "[...] não deve apenas ajudar os estudantes a aprender certas formas e conhecimento e de técnicas, mas também convidá-los a refletirem sobre como essas formas de conhecimento e de técnicas devem ser trazidas à ação." (SKOVSMOSE, 2004, p. 53).

Utilizamos os termos educação, matemática e finanças de maneira a se relacionarem, o que propiciará uma abordagem social, histórica e crítica das relações humanas. Essas relações denotam uma perspectiva humanista, em que a matemática deixa de ser apenas teórica e demonstrativa e passa a ser percebida como uma construção humana, resultado de experimentações, movidas pela necessidade e curiosidade do homem. Groenwald, Silva e Mora (2004, p. 37) aduzem que "A Matemática possui um papel social importante na inclusão das pessoas na sociedade. Ensinar Matemática é fornecer instrumentos para o homem atuar no mundo de modo mais eficaz, formando cidadãos comprometidos e participativos".

Skovsmose propõe a perspectiva teórica de educação crítica na educação matemática, corroborando para uma nova abordagem, dentro da educação matemática: a educação matemática crítica. Deste modo, o "processo educacional está relacionado a problemas existentes fora do universo educacional” (SKOVSMOSE, 2001, p 19). A matemática, segundo Brouwer, citado por Skovsmose (2001, p 25), "é uma construção humana" e, portanto a matemática deve levar em conta as relações entre aluno e professor.

Portanto, o educador não é o único controlador no processo educacional, todavia alunos e professores precisam se comunicar para que haja um ambiente propício para o aprendizado. Para Le Coadic (2004, p.11), a comunicação é "o processo intermediário que permite a troca de informação entre as pessoas [...]". Logo, o processo ensino-aprendizagem é permeado pelas relações interpessoais, tanto pela relação aluno-professor quanto pela relação aluno-aluno.

A aprendizagem dialógica ocorre a partir de um ato comunicativo, em oposição à aprendizagem tradicional, permitindo um maior desenvolvimento do educando. Na sala de aula, o professor é quem domina o processo de comunicação e, por isso, ele deve proporcionar meios para que o diálogo aconteça. Como a comunicação é uma relação interpessoal, esta ocorre entre sujeitos distintos com personalidades e pensamentos diferentes, assim, cada um possuirá uma perspectiva própria sobre o objeto da comunicação. Neste contexto, surge a necessidade do diálogo, por meio do qual se formarão interconexões sobre o objeto comunicado, ou seja, a união de perspectivas diferentes produzirá conhecimento a cerca do objeto. 
Considera-se o diálogo de qualidade como algo mais abrangente que a simples comunicação dos conteúdos, uma vez que ele permite a interação entre os sujeitos. Espera-se que a relação entre professor e aluno seja permeada pela ação, reflexão e interação, em torno do conhecimento.

Para que ocorra aprendizagem, o diálogo deve possuir três aspectos determinantes para sua qualidade, a saber: realizar uma investigação; correr riscos, quanto a natureza imprevisível dos desdobramentos de um diálogo; e promover a igualdade, no que se refere ao relacionamento interpessoal (ALRO; SKOVSMOSE 2010, p. 123).

É possível encontrar esses aspectos na aprendizagem dialógica, mas, não na aprendizagem tradicional. Entendemos que, na aprendizagem tradicional, a relação entre o professor e os alunos é uma via de mão única, na qual o professor é o emissor do conhecimento e os alunos são receptores desse. $O$ professor e o aluno apresentam-se em condições desiguais, visto que 0 primeiro é considerado e o segundo uma "mera tábua rasa", o que o colocaria em uma situação de desvantagem.

\section{JOGO COMO ATIVIDADE LÚDICA}

Visando a modificação na prática de ensino da disciplina de Matemática, desenvolvemos um jogo que utiliza o programa RPG maker, em que os alunos participam ativamente da construção de seu conhecimento. A utilização de jogos para a promoção da aprendizagem é útil, pois contribuem com a memória, o desenvolvimento intelectual, atenção e observação (Rosa, 2004).

Estamos em uma época em que as pessoas estão conectadas por meio de várias redes sociais e jogos. A escola e os alunos, por sua vez, não podem se tornar alienados a esse fato. Muito pelo contrário, os professores devem rever as práticas e integrá-las a essa realidade, mantendo os alunos interessados e motivados.

Os trabalhos de Almeida (1984) e Rosa (2004) discutem sobre a importância do uso de jogos em sala de aula para a promoção de um aprendizado significativo. Segundo Rosa (2004, p.22), "diversas teorias, dadas como difíceis, quando aplicadas através de jogos revelavam facilidades". Além de, no âmbito disciplinar, conseguir prender a atenção dos alunos em algo que lhes é interessante. Rosa também ressalta a importância da postura do professor durante toda a execução desse tipo de atividade, em que o jogo é utilizado como facilitador da aprendizagem. Para ele, o professor deve estar preparado, ou perderia seu objetivo inicial e não passaria de mais um jogo para os alunos.

Em relação ao tipo de jogo escolhido, utilizamos o RPG - Role Playing Game - que é uma modalidade de jogo em que se usa a representação com fundamento. O jogo de RPG criado nessa atividade segue a teoria construcionista de Papert, que segundo Rosa (2004) é "uma teoria de aprendizagem que rejeita a ideia de que, para que ocorra uma melhor aprendizagem, o que deve ser feito é o aperfeiçoamento da instrução".

A atividade foi aplicada por professores de Matemática com alunos do ensino fundamental (ciclo II) e está dividida em dois momentos, a saber: a experimentação, em que os alunos realizaram a leitura de um texto com instruções para o manuseio do jogo e o momento de manipulação deste, e a utilização da pesquisa, visto que os alunos utilizaram a internet para resolver as questões contidas no jogo. É necessário que os alunos tenham em mãos papel e caneta 
para eventuais cálculos. A duração da atividade é de três aulas de 50 minutos, podendo ser aplicado em turmas de ensino fundamental e médio. No ensino fundamental, o jogo pode ser usado como ferramenta de descoberta de conceitos e, no ensino médio, a atividade poderá ser aplicada como alternativa de resgate de conteúdos contemplados e a introdução do assunto moeda/dinheiro em sala de aula. Os professores de Matemática que aplicaram a atividade relataram suas impressões/observações ao pesquisador. $O$ objetivo desse jogo é promover o debate sobre a construção do conceito de moeda/dinheiro, assim como, os elementos em torno desse assunto.

O jogo se passa, historicamente, no período medieval e possui um personagem principal, um herói, que possui um desafio: percorrer vinte casas e responder a vinte e cinco perguntas sobre o assunto moeda/dinheiro. O jogo apresenta, inicialmente, uma tela com as opções "Nova Partida", "Continuar" e "Sair".

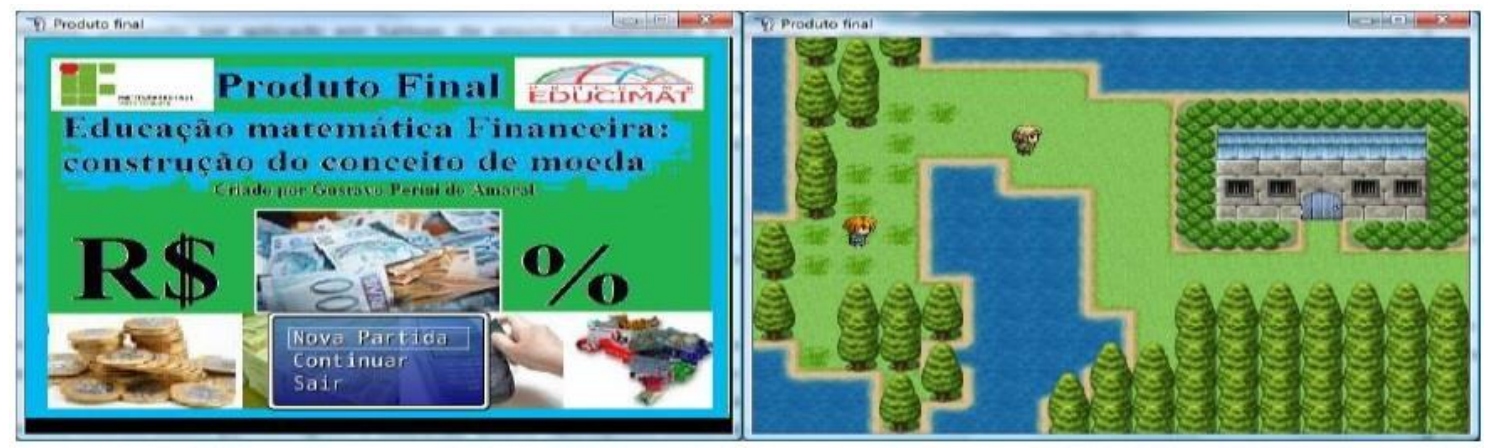

Figura 1: Tela inicial do jogo desenvolvido

O objetivo do jogo é conseguir reunir os seis itens referentes aos grupos cálculo, problema, história, pesquisa e modelagem, além de responder curiosidades sobre o assunto moeda/dinheiro. Para isso, é necessário que o aluno possua prévio conhecimento teórico sobre porcentagem e sobre as quatro operações, conteúdos esses previstos pelo PCN de Matemática do Ensino Fundamental.

A atividade está dividida em três etapas. A primeira etapa é composta por cinco casas e seis perguntas, a segunda é composta por oito casas e doze perguntas e a última por sete casas e sete perguntas. As questões estão divididas em seis grupos, a saber: quatro questões de cálculo, três problemas, sete questões históricas, quatro questões para pesquisa, quatro curiosidades e três questões de modelagem. Ao responder corretamente cada questão, o personagem ganhará $R \$ 10$ e receberá, automaticamente, um item relacionado ao grupo que a questão pertence (cálculo, problema, história, pesquisa, curiosidade ou modelagem) e o sujeito que realizou a pergunta desaparece definitivamente do jogo. 


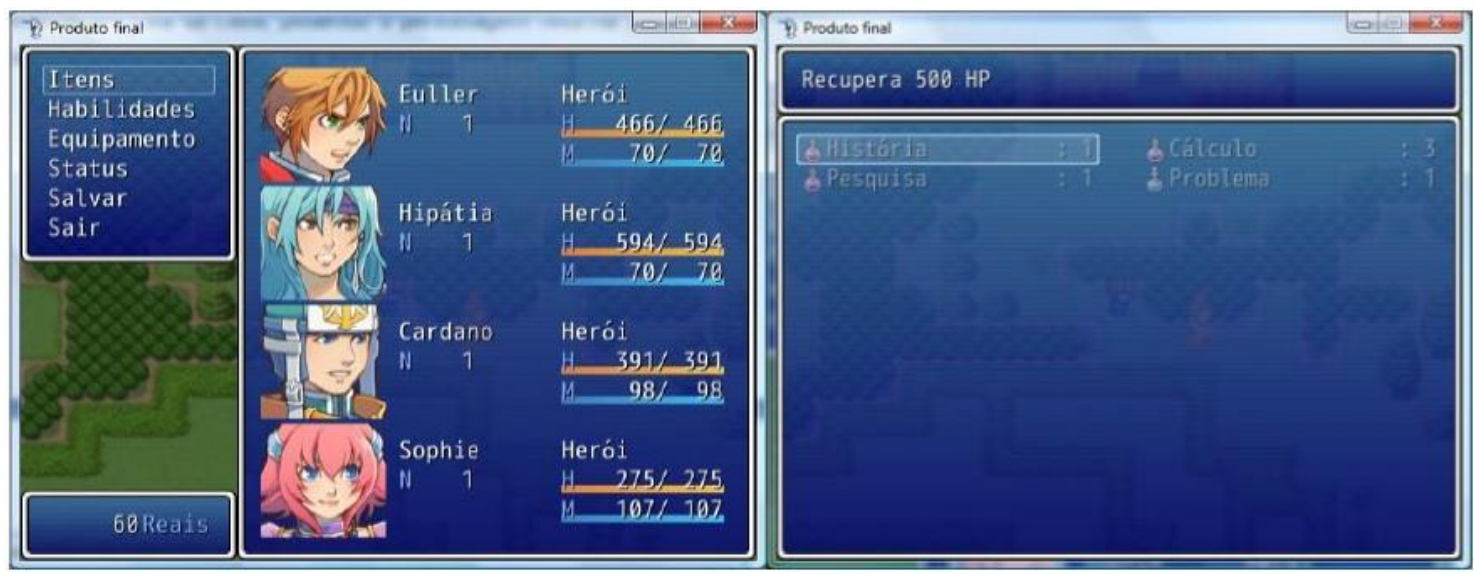

Figura 2: Menu do jogo e participantes

Caso erre a resposta, o personagem perde $\mathrm{R} \$ 5$ e o sujeito que realizou a pergunta desaparece até que o personagem saia da casa, podendo o personagem retornar para dentro da casa e realizar nova tentativa.

Durante a atividade, os alunos encontraram questões de múltipla escolha e questões com sentenças de verdadeiro e falso. As questões, apresentadas, trabalham com informações históricas, conhecimentos gerais, o conceito de proporção, taxa de juro, desconto, aumento, parcelamento, juro simples e composto.

As questões contidas no jogo têm como objetivo promover o diálogo e a reflexão entre o professor e os alunos. As questões debatem desde a história da moeda até os conceitos matemáticos. Encontramos questões sobre a história da moeda no Brasil, desde as patacas até o Real. Outras questões abordam conceitos matemáticos como juro simples e composto, taxa de juro, porcentagem e proporção, função e equação. Para resolver as questões que se apresentam como problemas e afirmações históricas, os alunos utilizaram diagramas, método da tentativa e erro e o processo de investigação por meio de pesquisa na internet, para interpretar os enunciados. Algumas questões apresentam dados relevantes para a resolução das questões e informações desnecessárias, cabendo ao aluno à decisão sobre a utilização das informações que podem ser utilizadas para resolver a questão.

O professor deve preparar discussões a respeito de cada questão do jogo. Como proposta inicial para se discutir, o professor começará com o significado de uma pesquisa, o que pesquisar, como pesquisar, onde pesquisar, quais fontes são confiáveis, e o que se deve levar em conta durante a pesquisa. O mediador poderá trabalhar o significado de uma investigação, por meio de debates, e pesquisar sobre a história da moeda no Brasil. Em determinadas questões os alunos registram os cálculos no papel e o docente coletará os modelos de resolução das questões para discutir a variedade de caminhos que se percorre para encontrar o resultado. A discussão sobre as resoluções encontradas pelos alunos nos remete a pensar e questionar a respeito das soluções de cada questão, em que o professor de Matemática apresenta um caminho e os alunos, sem questionar, entendem que essa solução é única. O professor, ao proporcionar momentos de discussão, promove a construção de outra perspectiva a respeito da disciplina de matemática. 0 aluno passa a enxergar a matemática como disciplina humana e os resultados deixam de se apresentar como verdades absolutas e passam a ser questionados. 


\section{CONCLUSÕES}

Os alunos evidenciaram o interesse pelo conceito de moeda, tendo em vista a participação e o diálogo ocorrido nas atividades, ao articular o saber formal, adquirido na escola, e o informal, adquirido na prática. Esse interesse se comprova com a relação de cumplicidade entre o pesquisador, os alunos e a professora responsável. Durante o diálogo, na primeira atividade, os sujeitos envolvidos na pesquisa - alunos, pesquisador e professora responsável - trataram a construção histórica do conceito de moeda como uma construção social, em que as relações interpessoais são norteadas pelos significados da moeda/dinheiro. Percebemos que os alunos manifestaram interesse e sensibilidade a respeito do tema "a construção histórica do conceito de moeda", desde o escambo até o dinheiro eletrônico. $O$ trato de algumas questões em torno dessa construção histórica fez com que os alunos percebessem que o termo moeda sugere algo muito além do que a simples relação entre comprar e vender, em que o dinheiro seria uma representação de um valor, mas uma construção de moeda como um conceito advindo da necessidade, interesse e das relações entre pessoas.

O tema moeda/dinheiro, debatido durante esta pesquisa, não trata os alunos como sujeitos passivos, visto que propomos uma nova abordagem com relação ao currículo de Matemática, em que a disciplina deixa de tratar o conhecimento como algo fragmentado. Dessa maneira, a matemática escolar passa a intermediar a relação entre a matemática acadêmica e a matemática do cotidiano, em que as disciplinas se interagem para construção de sujeitos críticos. Os conceitos matemáticos deixam de ser ensinados de maneira fragmentada e passam a ser tratados como conceitos indissociáveis do contexto em que se apresentam.

Retomamos, conforme anunciamos no início deste artigo, alguns conceitos importantes que observamos na aplicação do jogo, tais como a criação e a experiência, que tornam os alunos mais ativos, que interagem de forma mais dinâmica, contribuindo para o ensino de matemática, que se mostra mais ligado às questões do cotidiano, fato este comprovado pelos autores que pesquisamos e citamos ao longo do texto. Todos eles apontam para um ensino de matemática transversal, que dialogue com outras disciplinas do currículo e desperte, no aluno, a curiosidade para saber lidar com questões monetárias, como foi o escopo desta pesquisa investigativa.

Esta pesquisa se apoia na reorganização do currículo. Ela também desenvolve relações de diálogo entre aluno e currículo, professor e escola, aluno e professor, aluno e escola, currículo e escola dentre outras conexões. Dessa maneira, propomos um jogo, para professores de matemática, que apresenta o tema moeda/dinheiro. Ele foi criado por meio do programa RPG Maker, como uma das metodologias alternativas para o ensino de matemática. O game teve como finalidade aproximar a Educação Matemática Financeira do cotidiano escolar e introduzir o assunto "a construção histórica do conceito de moeda/dinheiro" de maneira lúdica e investigativa.

\section{REFERÊNCIAS}

1. ALMEIDA, P.N. de. Dinâmica Lúdica: jogos pedagógicos. São Paulo: Loyola, 1984.

2. ALRO, H.; SKOVSMOSE, O.. Diálogo e aprendizagem em educação matemática. 2. ed. Belo Horizonte: Autêntica, 2010.

3. BASTOS, A.S.A.M.. Noções de porcentagem, de desconto e de acréscimo na Educação de 
jovens e adultos. 2007. 145 f. Dissertação (Mestrado Ensino de Ciências e Matemática) Universidade Cruzeiro do Sul, São Paulo, 2007.

4. BRASIL. Ministério da Educação. Parâmetros Curriculares Nacionais: Matemática. Brasília, 1999.

5. D’AMBRÓSIO, U.. Etnomatemática: Elo entre as tradições e a modernidade. Belo Horizonte: Autêntica, 2001.

6. FREIRE, P.. Educação e mudança. Rio de Janeiro: Paz e Terra, 2003.

7. GROENWALD, C.L.O.; SILVA, C.K.; MORA, C.D.. Perspectivas em Educação Matemática. ACTA SCIENTIAE, v.6, n.1, p. 37 - 55, Canoas, RS: Editora Ulbra, jan./jun. 2004.

8. LE COADIC, Yves-François. A ciência da informação. 2. ed. Brasília: Brinquet Lemos, 2004.

9. ROSA, M.. Role Playing Game: uma tecnologia lúdica para aprender a ensinar Matemática. 2004. 170 p. Dissertação (Mestre em Educação Matemática) - Universidade Estadual de São Paulo, São Paulo, 2004.

10. SKOVSMOSE, O.; Educação Matemática Crítica: A Questão da Democracia. Tradução de Abgail Lins e Jussara de Loiola Araújo. 3. ed. Campinas, SP: Editora Papirus, 2010.

11. SKOVSMOSE, O.. Matemática em ação. In: BICUDO, M. e BORBA, M.C. (ORGS.) Educação matemática: pesquisa em movimento, p.30-57. São Paulo: Cortez, 2004.

12. SKOVSMOSE, O.. Landscapes of Investigation. ZDM, v. 33, n. 4, p.123-132, ago. 2001. 